https://doi.org/10.4314/ijs.v22i1.16

Ife Journal of Science vol. 22, no. 1 (2020)

\title{
MORIN ATTENUATES DUTASTERIDE/TAMSULOSIN-INDUCED HEPATIC OXIDATIVE STRESS IN RAT
}

\author{
Olayinka, E. T. ${ }^{1}$, Adewole, K. E. ${ }^{2} \%$ \\ ${ }^{1}$ Biochemistry Unit, Department of Chemical Sciences, Faculty of Natural Sciences, Ajayi Crowther University, PMB \\ 1066, Oyo, Oyo State, Nigeria. Email address: ebenezertundeolayinka2gmail.com. ${ }^{2 *}$ Department of Biochemistry, \\ Faculty of Basic Medical Sciences, University of Medical Sciences Ondo City, Ondo State Nigeria. \\ *Author for correspondence; e-mail address: kayowolemi@gmail.com \\ (Received: $19^{\text {th }}$ November, 2019; Accepted: $17^{\text {th }}$ February, 2020)
}

\section{ABSTRACT}

\begin{abstract}
Dutasteride-Tamsulosin (DUT-TAM) is a combination drug for the treatment of symptoms of prostate enlargement (benign prostatic hyperplasia, BPH). Despite the efficacy, it is associated with some side effects, including hepatotoxicity. Therefore, this study investigated the attenuative effects of morin on DUT-TAMinduced organ toxicity. Twenty four male rats were divided into 4 groups (A-D) consisting of 6 animals each. Group A animals (control) were given olive oil, Group B animals were administered with DUT-TAM (5.4 $\mathrm{mg} / \mathrm{kg}$ body weight of dutasteride $+3.4 \mathrm{mg} / \mathrm{kg}$ body weight of tamsulosin), Group C were given morin (100 $\mathrm{mg} / \mathrm{kg}$ body weight) while group D animals were administered DUT-TAM and morin $(5.4 \mathrm{mg} / \mathrm{kg}$ body weight dutasteride $+3.4 \mathrm{mg} / \mathrm{kg}$ body weight of Tamsulosin and $100 \mathrm{mg} / \mathrm{kg}$ body weight of morin). All the administrations were carried out orally for 14 days. DUT-TAM caused a significant increase in plasma bilirubin, aspartate aminotransferase (AST) and alanine aminotransferase (ALT) by $62 \%, 45 \%$ and $18 \%$ in the DUT-TAM treated group respectively, compared with the control $(\mathrm{P}<0.05)$. However, treatment with morin significantly decreased the DUT-TAM-induced increase in plasma bilirubin concentration as well as AST and ALT activities. Furthermore, DUT-TAM administration decreased the activities of hepatic superoxide dismutase (SOD), catalase (CAT), glutathione-S-transferase (GST), as well as hepatic concentration of ascorbic acid and reduced glutathione (GSH) by 58\%, 54\%, 59\%, 46\% and 63\% respectively, but increased malondialdehyde (MDA) level by $49 \%$ relative to the control $(\mathrm{P}<0.05)$. However, treatment with morin significantly ameliorated the observed changes in these antioxidant parameters $(\mathrm{P}<0.05)$. These data suggest that morin protects against hepatic toxicity, as well as oxidative stress induced by dutasteride-tamsulosin in rats.
\end{abstract}

Keywords: Dutasteride, Tamsulosin, Prostate enlargement, Oxidative stress, Liver

\section{INTRODUCTION}

Dutasteride-Tamsulosin (DUT-TAM) is a frontline drug for managing prostate enlargement (benign prostatic hyperplasia, BPH) common in men older than 40 years (Miller and Tarter, 2009; Kurczewski et al., 2017). It is a combination of 2 drugs, dutasteride and tamsulosin; while dutasteride $(5 \alpha, 17 \beta)-\mathrm{N}\{2,5$, bis (trifluoromethyl) phenyl $\}-3$-oxo-4-azaandrost-1-ene-17carboxamide), (Figure 1), is a $5 \alpha$-reductase inhibitor (5ARI), tamsulosin, (R)-5[2-[[2-(2Ethoxyphenoxy) ethyl] amino] propyl]-2methox y benzenesulfon a mide monohydrochloride, (Figure 2), is an $\alpha 1$ adrenergic blocking agent ( $\alpha$-blocker), Roehrborn et al., (2015). Benign prostatic enlargement, which results from benign prostatic hyperplasia, leads to lower urinary tract symptoms (LUTS), especially in men above 40 years (Kurczewski et al., 2017). Treatment with DUT-TAM improves the symptoms of BPH and LUTS, which helps in cutting down BPH-associated surgical procedures. Although various studies have confirmed the efficacy of dutasteride, negative effects have however been reported, these include reduced libido, ejaculatory dysfunction, impotence and gynecomastia (Roehrborn et al., 2002). For, tamsulosin, the unwanted effects include asthenia, dizziness, headache and postural hypotension (Roehrborn et al., 2008). Long-term treatment with dutasteride therapy has been found to cause increased blood glucose, glycated haemoglobin, total cholesterol and low density lipoprotein levels, with increased activity of plasma alanine amino transferase (ALT) and aspartate aminotransferase (AST) (Traish et al., 2017). Dutasteride has also been reported to cause liver inflammation and negative alteration of the histological architecture of mice liver, an indication that it is possibly hepatotoxic (Mohamadetal., 2017). 
Several indices, such as inflammation, diet, genetic modification, and oxidative factors have been implicated in the aetiology of BPH (Minciullo et al.,2015). Oxidative stress and damage to tissue of the prostate may cause abnormal cell growth which can lead to hyperplastic growth. Inflammation of the prostate can result in production of reactive oxygen species (ROS) and reactive nitrogen species, (RNS) (Hamid et al., 2011). Convincing scientific evidences suggest that micronutrient supplementation, including plant-derived molecules, may help to restore systemic antioxidant which can enhance the treatment results of $\mathrm{BPH}$ subjects (Udensi and Tchounwou, 2016). Morin (Figure 3) is a bioflavonoid chemically referred to as $3,5,7,2^{\prime}, 4^{\prime}$ pentahydroxy flavone, it was first isolated from the plant family Moraceae, which are commonly used as traditional medicinal herbs (Sreedharan and Venkatachalam, 2009). Morin has also been found in Prunus dulcis, Chlorophora tinctoria, (Ricardo et al., 2001$)$, Psidium guajava (Rattanachaikunsopon and Phumkhachorn, 2010), tea, cereal grains, fruits and in vegetables (Kang et al., 2004). Studies have revealed that morin exhibits antioxidant properties and offers protection towards hydrogen peroxide-induced oxidative stress (Zhang et al., 2009). It has also been reported that morin exhibits antioxidative, antiinflammatory and anti-proliferative potentials in different experimental models (Middleton et al., 2000). The feasibility of co-administration of anticancer drugs for treating BPH and antioxidants as a strategy to protect tissues from agents-inducing oxidative stress has been demonstrated (Joshi et al., 2007). Based on the pharmacological properties of morin, this study hypothesizes that morin can protect against possible hepatotoxic effects of DUT-TAM. The objective of this study therefore, is to evaluate the ameliorative potentials of morin on dutasteridetamsulosin-induced hepatotoxicity and oxidative stress in rats.

\section{MATERIALS AND METHODS Chemicals and Reagents}

Dutasteride and tamsulosin hydrochloride (Duodart $^{\mathbb{B}}$ ) is a product of Catalent, Schorndorf $\mathrm{GmbH}$, Germany. 1-chloro-2, 4-dinitrobenzene (CDNB), adrenaline (epinephrine), Glutathione
(GSH), 5', 5'-dintrobenzoic acid (DTNB) and thiobarbituric acid (TBA) are products of Sigma Chemical Company (London, UK). Assay kits for AST, ALT and total bilirubin are products of Agape Diagnostics, Switzerland GmbH. Other reagents and chemicals were of analytical grade and were purchased from British Drug House, London.

\section{Experimental Rats}

Male Wistar rats (120-140g) used for this study were purchased from Ladoke Akintola University, College of Health Sciences, Osogbo, Nigeria. The animals were kept in woody wire meshed cages, given free access to commercial animal feed (Vital feed $^{\mathbb{B}}$ ) and clean water ad libitum. They were acclimatized for two weeks before the onset of treatment. Animal treatment conformed to the guidelines of the National Institute of Health (NIH publication 85-23, 1985) for laboratory animal care and use in line with the rules of the Ethical Committee of the Ajayi Crowther University, Oyo, Oyo State Nigeria.

\section{Experimental Design (Grouping of Rats and Administration of Drug)}

Twenty four animals were randomly grouped into 4 (A-D), $n=6$ per group. Group A which served as the control were given olive oil, Group B animals were administered with DUT-TAM $(5.4 \mathrm{mg} / \mathrm{kg}$ body weight of dutasteride and $3.4 \mathrm{mg} / \mathrm{kg}$ body weight of tamsulosin), animals in Group C were given morin ( $100 \mathrm{mg} / \mathrm{kg}$ body weight), and Group $\mathrm{D}$ animals were administered DUT-TAM and morin (DUT-TAM, $5.4 \mathrm{mg} / \mathrm{kg}$ body weight of dutasteride $+3.4 \mathrm{mg} / \mathrm{kg}$ body weight of tamsulosin + Morin, $100 \mathrm{mg} / \mathrm{kg}$ body weight). The dose of the drug (DUT-TAM) is the therapeutic dose, while that of morin is the recommended dose from literature (Kuzu et al., 2019; Olayinka et al., 2019). The vehicle for dissolving both morin and DUT-TAM was olive oil and all administration was by oral gavage, using oral intubator, once per day for 14 days. Rats were then sacrificed $24 \mathrm{hr}$ following the last administration.

\section{Preparation of Plasma and Post Mitochondrial Fraction}

Animals were sacrificed by cervical dislocation, 
and Ganjoo, 2015).

\section{Determination of Hepatic Reduced Glutathione Content}

The GSH level in the samples was estimated by the method described by Jollow et al. (1974). Briefly, distilled water $(900 \mu \mathrm{l}), 100 \mu \mathrm{l}$ of sample and $1.5 \mathrm{ml}$ of sulphosalicylic acid (4\%) were mixed, left on the bench for $5 \mathrm{~min}$ and filtered; the filtrate $(500$ $\mu \mathrm{l})$ was added to $2 \mathrm{ml}$ of phosphate buffer $(0.1 \mathrm{M})$ and, $250 \mu \mathrm{l} 0.04 \%$ DTNB (in $0.1 \mathrm{M}$ phosphate buffer, $\mathrm{pH}$ 7.4). The absorbance was read at 412 $\mathrm{nm}$, with a blank reference, while the GSH level was interpolated using the standard curve generated from using different concentrations of GSH.

\section{Estimation of Hepatic Ascorbic Acid Level}

The ascorbic acid concentration in hepatic tissue was estimated using the method described by Jagota and Dani (1982). Briefly, $500 \mu$ l of sample and $800 \mu \mathrm{l}$ of $10 \%$ TCA were mixed vigorously, by shaking, and then placed on ice for about $5 \mathrm{~min}$. The mixture was centrifuged at $2000 \times \mathrm{g}$ for 10 min, after which $1000 \mu \mathrm{l}$ of the resulting supernatants and $200 \mu \mathrm{l}$ of diluted Folin's reagent (Folin's reagent: distilled $\mathrm{H}_{2} \mathrm{O}, 1: 10$ ) were added together and stirred vigorously. The absorbance of the resulting blue-colored solution was recorded after $10 \mathrm{~min}$ at $760 \mathrm{~nm}$. The hepatic ascorbic acid concentration $(\mu \mathrm{g} / \mathrm{ml})$ was obtained by interpolation from the ascorbic acid standard curve generated using varying concentrations of standard ascorbic acid

\section{Assessment of Hepatic Lipid Peroxidation}

Hepatic lipid peroxidation was estimated by the quantification of malondialdehyde (MDA) levels with the aid of 2-thiobarbituric acid in organ homogenates (Varshney and Kale, 1990). Briefly, $3.2 \mathrm{ml}$ Tris- $\mathrm{HCl}$ buffer, $1.0 \mathrm{ml}$ of $30 \%$ TCA, $0.8 \mathrm{ml}$ of samples, $1.0 \mathrm{ml}$ of $0.75 \%$ TBA were mixed. The temperature of the mixture was raised to 95 ${ }^{\circ} \mathrm{C}$ and maintained at same for $1 \mathrm{hr}$ using a water bath. The mixture was then centrifuged at 3000 rpm, after cooling on ice. The supernatant was retrieved and the absorbance read against distilled water blank at $532 \mathrm{~nm}$. The level of lipid peroxidation in nmole/mg protein was estimated using the following equation:

$\mathrm{MDA}=$

$\frac{\text { Abs } x \text { Volume of reaction mixture }}{\text { E532 } x \text { Volume of sample } x \text { mg protein }}$

Where: $\mathrm{E}_{532}=$ molar extinction coefficient for MDA, which is $1.56 \times 10^{5} / \mathrm{M} / \mathrm{cm}$

\section{Histopathology of the Liver}

Histopathological study was done as described by Krause (2001). Briefly, liver samples were fixed in $10 \%$ formalin for $24 \mathrm{hr}$ and dehydrated through ascending grades of ethanol, and fixed in paraffin wax. Sections of about $5 \mu \mathrm{m}$, were cut on a microtome and stained in aqueous dyes. Balsam mounting medium was put on the liver section and thin glass cover slips were placed on the mounting medium and the underlying tissue sections allowed to dry and later observed using x 720 magnification of the microscope and the photomicrographs were taken in a bright field.

\section{Statistical Analysis}

The data were expressed as Mean \pm SD. The data were analyzed using one way analysis of variance, with Duncan multiple range test used to compare control and treatment groups using SigmaPlot ${ }^{\circledR}$ (Systat Software Inc, CA, USA). For statistical significance, $p<0.05$ were considered.

\section{RESULTS}

\section{Protective Effects of Morin on DUT-TAM- Induced Hepatotoxicity in Rats}

Table 1 shows data on the ameliorative potential of morin on DUT-TAM-induced alterations in the concentrations of bilirubin, as well as the activities of ALT and AST in the plasma of rats. DUT-TAM significantly increased the level of bilirubin in the plasma by $62 \%$ and the activities of AST and ALT by $45 \%$ and $18 \%$ respectively, relative to the control. Morin caused a significant increase in these parameters when administered alone. However, administration of morin with DUT-TAM (co-treated group) significantly $(\mathrm{P}<0.05)$ ameliorated the increased plasma bilirubin, AST and ALT levels relative to DUTTAM treated group. 
and blood was obtained via ocular puncture into heparinized sample bottles. From the blood samples, plasma was obtained by centrifugation for 10 minutes at $4000 \mathrm{xg}$ (Celcom bench centrifuge), and kept at $-20{ }^{\circ} \mathrm{C}$ for subsequent biochemical analyses. After the rats have been carefully dissected, the livers were removed, cleared of fat and washed in $\mathrm{KCl}\left(0^{\circ} \mathrm{C}\right.$ and $\left.1.15 \%\right)$. The organs were homogenized in potassium phosphate buffer, $\left(0{ }^{\circ} \mathrm{C}, 0.01 \mathrm{M}, \mathrm{pH} \quad 7.4\right)$, centrifuged at $12,000 \times \mathrm{g}$ for $10 \mathrm{~min}$ at $0{ }^{\circ} \mathrm{C}$ and the post-mitochondrial fractions (PMF) obtained for further analyses.

\section{Determination of Protein Concentration}

Concentration of protein was estimated as described by Gornall et al., (1949). The reaction mixture was made up of $2 \mathrm{ml}$ of biuret reagent plus $0.5 \mathrm{ml}$ of suitably diluted sample, in the blank, $0.5 \mathrm{ml}$ of distilled water was used in place of sample. Estimation of the protein concentration was done by interpolation from the standard curve prepared using varied concentration of bovine serum albumin.

\section{Assays for Biomarkers of Hepatotoxicity}

The plasma levels of biomarkers of liver damage ALT, AST and bilirubin were determined using Agape Diagnostics ${ }^{\circledR}$ following the manufacturer's protocol. Activities of plasma AST and ALT were estimated using the method of Reitman and Frankel (1957) while that of bilirubin was done as described by Tietz et al., (1994).

\section{Determination of Hepatic Catalase Activity}

Hepatic catalase activity was estimated according to the method described by Sinha (1972). The assay mixture which was made up of $2.5 \mathrm{ml}$ of $0.01 \mathrm{M}$ phosphate buffer ( $\mathrm{pH} 7.0), 2 \mathrm{ml} \mathrm{H}_{2} \mathrm{O}_{2}$ solution ( $800 \mu$ moles), $0.5 \mathrm{ml}$ of suitably diluted liver PMF (1:50) was mixed, and $1 \mathrm{ml}$ of it was added into $2 \mathrm{ml}$ acetic acid/dichromate solution, at intervals of $1 \mathrm{~min}$, to estimate the quantity of the hydrogen peroxide left. The chromic acetate generated was quantified at $570 \mathrm{~nm}$ with the amount of hydrogen peroxide left obtained by interpolation from the hydrogen peroxide standard curve. The activity of catalase was expressed as micromole of hydrogen peroxide used up every $60 \mathrm{sec}$, by $1 \mathrm{mg}$ of protein.

\section{Determination of Hepatic Superoxide Dismutase Activity}

The activity of superoxide dismutase (SOD) was estimated using the method of Misra and Fridovich (1972). Five hundred $(500 \mu \mathrm{l})$ of the sample was diluted with $4.5 \mathrm{ml}$ of distilled $\mathrm{H}_{2} \mathrm{O}$. A portion of the diluted sample $(200 \mu \mathrm{l})$ was mixed with $2.5 \mathrm{ml}$ of carbonate buffer $(0.05 \mathrm{M}, \mathrm{pH} 10.2)$ and allowed to stay in the spectrophotometer to equilibrate, $0.3 \mathrm{ml}$ of freshly prepared epinephrine $(0.3 \mathrm{mM})$ was added to the mixture, following which the mixture was briskly mixed by inversion, and the rise in the value of absorbance at $480 \mathrm{~nm}$ recorded every $0.5 \mathrm{~min}$ for $2.5 \mathrm{~min}$. the blank contained distilled water in place of sample. Superoxide dismutase activity was estimated as follows:

\section{Percentage inhibition $=$ \\ $\left(\frac{\text { increase in absorbance of sample }}{\text { increase in absorbance of blank }}\right) \times 100$}

A unit of SOD activity is the quantity of SOD required to effect $50 \%$ inhibition of the oxidation of epinephrine (adrenaline) to adrenochrome in 1 min(Ahmad et al., 2019).

SOD activity (Unit/mg) $=\frac{\operatorname{SOD}(\text { Unit })}{\text { Protein }(m g)} x d f$

$\mathrm{df}=$ dilution factor

\section{Determination of Hepatic Glutathione-S- Transferase Activity}

The activity of GST was determined as described by Habig et al. (1974). Briefly, the constituents of the assay mixture include: $60 \mu \mathrm{l}$ of $0.1 \mathrm{M} \mathrm{GSH}$, $5.58 \mathrm{ml}$ of $0.1 \mathrm{M}$ phosphate buffer (pH 6.5), $300 \mu \mathrm{l}$ CDNB $(3.37 \mathrm{mg} / \mathrm{ml})$ and $30 \mu \mathrm{l}$ of liver PMF. The absorbance of the reaction mixture was recorded at $340 \mathrm{~nm}$ against the blank after 60 seconds. The activity of the enzyme in the sample was estimated as follows:

Activity of GST, in $\mu$ mole $/ \mathrm{min} / \mathrm{mg}$ protein $=$ $\left(\frac{\mathrm{Abs} / \mathrm{min}}{9.6}\right) \times \frac{1}{0.03 \times \text { protein }(\mathrm{mg})}$

Where: $9.6=$ molar extinction coefficient of S2,4-DNP-glutathione conjugate $\left(\mathrm{mmol}^{-1} \mathrm{~cm}^{-1}\right)$ and 0.03 is the volume of sample used (Chaudhary 
Table 1: Protective Effect of Morin on DUT-TAM-induced Changes in the Plasma Level of Bilirubin and the Activities of Aspartate aminotransferase (AST) and Alanine aminotransferase (ALT)

\begin{tabular}{|l|l|l|l|}
\hline Treatment Groups & Bilirubin $(\mathrm{mg} / \mathrm{dL})$ & AST $(\mathrm{U} / \mathrm{L})$ & ALT (U/L) \\
\hline Control & $2.06 \pm 0.15$ & $6.50 \pm 0.57$ & $97.50 \pm 0.58$ \\
\hline DUT-TAM & $5.40 \pm 0.10\left(61.85^{*} \%\right)^{*}$ & $11.77 \pm 0.23\left(44.77^{*} \%\right)^{*}$ & $119.50 \pm 1.05(18.41 \%)^{*}$ \\
\hline morin & $2.13 \pm 0.12^{*}$ & $7.18 \pm 0.22^{*}$ & $102.00 \pm 2.53^{*}$ \\
\hline $\begin{array}{c}\text { DUT-TAM }+ \\
\text { morin }\end{array}$ & $3.41 \pm 0.10^{*, a}$ & $8.22 \pm 0.19^{*, a}$ & $110.00 \pm 1.41^{*, a}$ \\
\hline
\end{tabular}

DUT-TAM= Dutasteride-Tamsulosin $(5.4 \mathrm{mg} / \mathrm{kg}$ body weight Dutasteride $+3.4 \mathrm{mg} / \mathrm{kg}$ body weight of Tamsulosin); Morin $=100 \mathrm{mg} / \mathrm{kg}$ body weight morin

The results are expressed as Means \pm SD for six rats in each group

$*=$ Significantly different from the control $(\mathrm{P}<0.05)$

${ }^{a}=$ Significantly different from Dutasteride-Tamsulosin group $(\mathrm{P}<0.05)$

Values in parenthesis represent percentage (\%) increase

Ameliorative Effect of Morin on DUT- respectively, compared to control $(\mathrm{P}<0.05)$. TAM-Induced Alterations in Hepatic Administration of morin alone has no effect on Catalase and Superoxide Dismutase in Rats

Table 2 shows data on the protective effect of morin on DUT-TAM induced alterations in hepatic catalase and SOD activities in rats. Hepatic SOD and catalase activities were significantly reduced in DUT-TAM group by $58 \%$ and $54 \%$ the activity of SOD but significantly lowered the activity of catalase relative to control. Cotreatment with morin and DUT-TAM, however, significantly $(\mathrm{P}<0.05)$ ameliorated the reduction in hepatic SOD and catalase relative to DUT-TAM treated rats.

Table 2: Protective Effect of Morin on DUT-TAM-induced Changes in the Activities of Hepatic Superoxide Dismutase (SOD) and Catalase in Rats

\begin{tabular}{|l|l|l|}
\hline Treatment Groups & Superoxide dismutase (Units) & $\begin{array}{c}\text { Catalase }\left(\mu \mathrm{mole} \mathrm{H}_{2} \mathrm{O}_{2}\right. \\
\text { consumed } / \mathrm{min})\end{array}$ \\
\hline Control & $14.60 \pm 0.55$ & $0.26 \pm 0.01$ \\
\hline DUT-TAM & $6.60 \pm 0.89(54.76 \%)^{*}$ & $0.12 \pm 0.01\left(53.84^{*} \%\right)^{*}$ \\
\hline Morin & $13.00 \pm 0.71$ & $0.22 \pm 0.01^{*}$ \\
\hline DUT-TAM + morin & $10.80 \pm 0.84^{*, a}$ & $0.20 \pm 0.01^{*, a}$ \\
\hline
\end{tabular}

DUT-TAM = Dutasteride-Tamsulosin $(5.4 \mathrm{mg} / \mathrm{kg}$ body weight Dutasteride $+3.4 \mathrm{mg} / \mathrm{kg}$ body weight of Tamsulosin); morin $=100 \mathrm{mg} / \mathrm{kg}$ body weight morin

The results are expressed as Means \pm SD for six rats in each group

$*=$ Significantly different from the control $(\mathrm{P}<0.05)$

${ }^{a}=$ Significantly different from Dutasteride-Tamsulosin group $(\mathrm{P}<0.05)$

Values in parenthesis represent percentage (\%) decrease

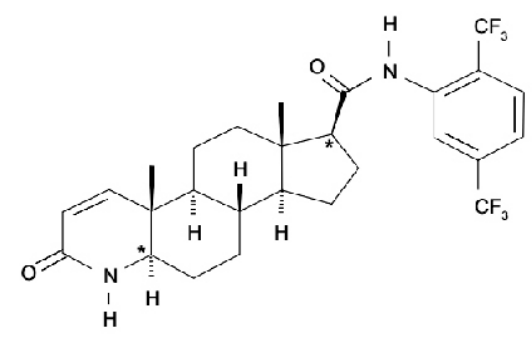

Figure 1: Structure of Dutasteride<smiles>COc1cc(Cl)ccc1OCCNCC(C)c1ccc(S(N)(=O)=O)c(OC)c1</smiles>

Figure 2: Structure of Tamsulosin 
<smiles>O=c1c(O)c(-c2ccc(O)cc2O)oc2cc(O)cc(O)c12</smiles>

Figure 3: Structure of Morin

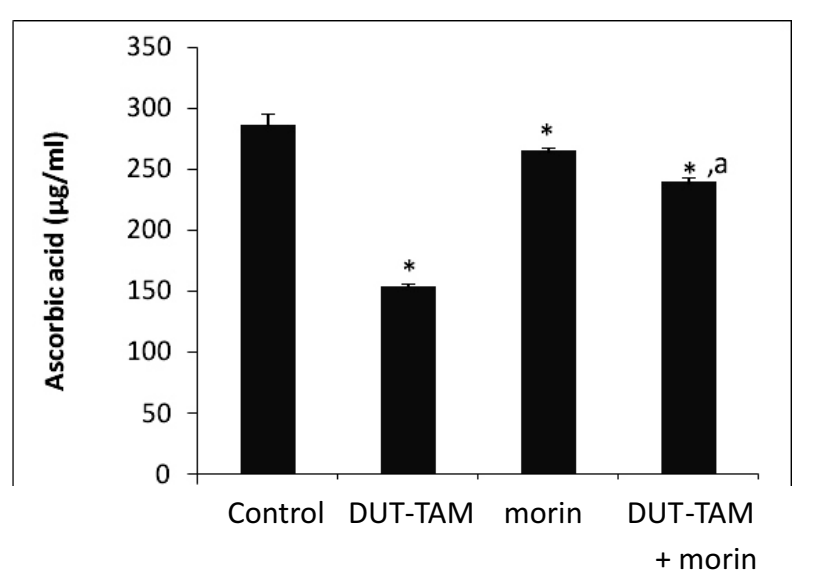

Treatment group $s$

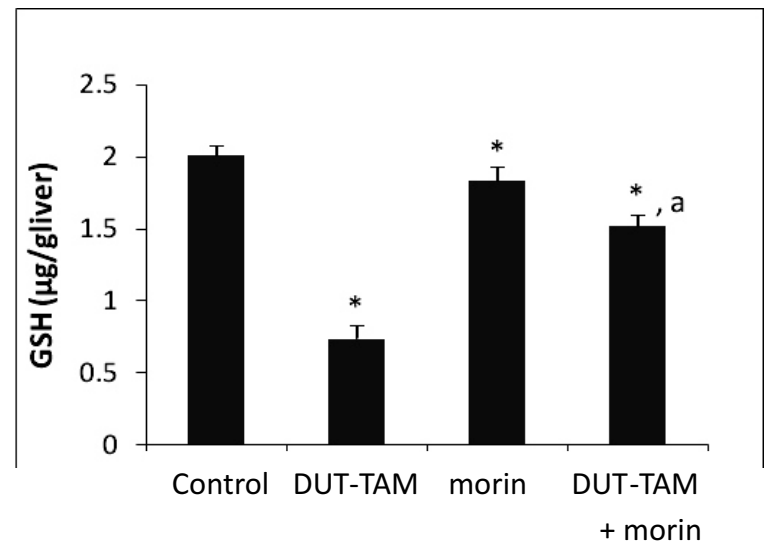

Treatment groups

Figure 4: Protective Effect of Morin on Dutasteride/Tamsulosin-induced Changes on the Level of Hepatic Ascorbic Acid and Reduced Glutathione (GSH) in Rats

DUT-TAM= Dutasteride-Tamsulosin $(5.4 \mathrm{mg} / \mathrm{kg}$ body weight Dutasteride $+3.4 \mathrm{mg} / \mathrm{kg}$ body weight of Tamsulosin); Morin $=100 \mathrm{mg} / \mathrm{kg}$ body weight morin

The results are expressed as Means \pm SD for six rats in each group

$*=$ Significantly different from the control $(\mathrm{P}<0.05)$

${ }^{a}=$ Significantly different from Dutasteride-Tamsulosin group $(\mathrm{P}<0.05)$

Protective Effect of Morin on DUT-TAMInduced Alterations in the Concentrations of Hepatic Ascorbic Acid and Reduced Glutathione in Rats

The protective capacity of morin on DUT-TAMinduced alterations in the concentrations of ascorbic acid and reduced glutathione are presented in figure 4. Following treatment with DUT-TAM, the hepatic ascorbic acid and reduced glutathione levels were significantly decreased when compared with the control group. The combined treatment of morin and DUT-TAM significantly $(\mathrm{P}<0.05)$ attenuated the reduction in hepatic ascorbic acid and GSH levels relative to DUT-TAM group.
Protective Capacity of Morin on DUTTAM-Induced Alterations in Hepatic Glutathione-S-Transferase and Lipid Peroxidation

The protective ability of morin on changes caused by dutasteride/tamsulosin in rats' hepatic GST and lipid peroxidation are presented in figure 5 . Results showed that GST activity was significantly reduced $(\mathrm{P}<0.05)$ in the DUT-TAM treated group, compared with the control animals. Administration of morin with DUT-TAM significantly ameliorated induced decrease in hepatic GST activity relative to the DUT-TAM treated group. However, the hepatic MDA was significantly increased $(\mathrm{P}<0.05)$ by DUT-TAM treatment, compared with the control. Co- 
treatment of morin and DUT-TAM significantly reduced the elevated hepatic MDA relative to the

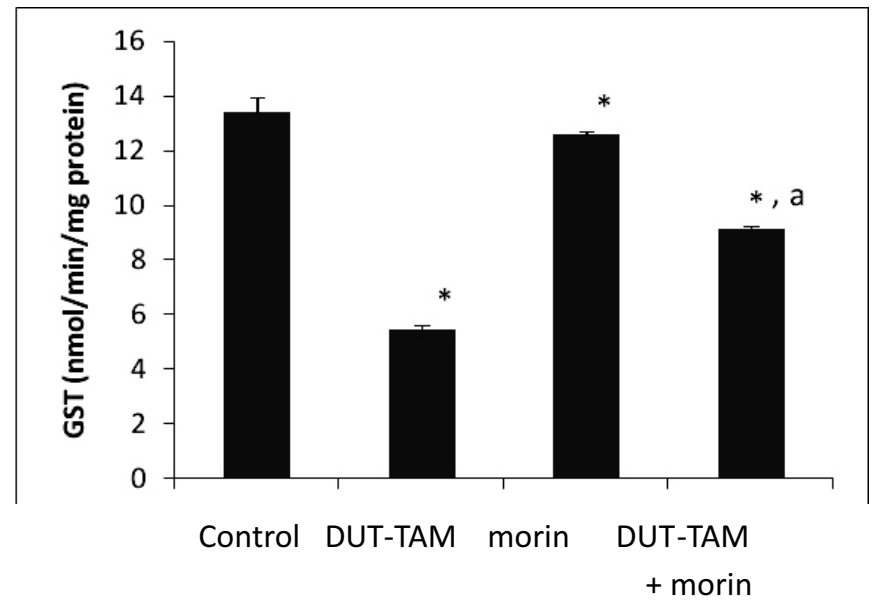

Treatment groups
DUT-TAM group.

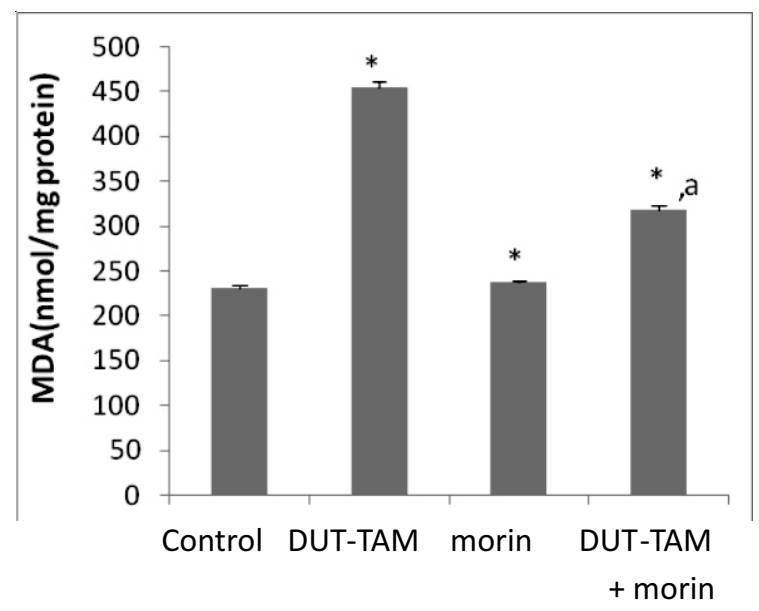

Treatment groups

Figure 5: Protective Effect of Morin on DUT-TAM-induced Changes in the Activity of Hepatic Glutathione-S-Transferase and Level of Hepatic Lipid Peroxidation in Rats

DUT-TAM $=$ Dutasteride $/$ Tamsulosin $(5.4 \mathrm{mg} / \mathrm{kg}$ body weight Dutasteride $+3.4 \mathrm{mg} / \mathrm{kg}$ body weight of Tamsulosin); morin $=100 \mathrm{mg} / \mathrm{kg}$ body weight morin

The results are expressed as Means \pm SD (range) for six rats in each group

$*=$ Significantly different $(\mathrm{P}<0.05)$ from the control

${ }^{a}=$ Significantly different $(\mathrm{P}<0.05)$ from DUT-TAM group

Effect of DUT-TAM and Morin on Liver Histology of Rats

The photomicrographs of hepatic tissue after treatments, based on experimental grouping, are
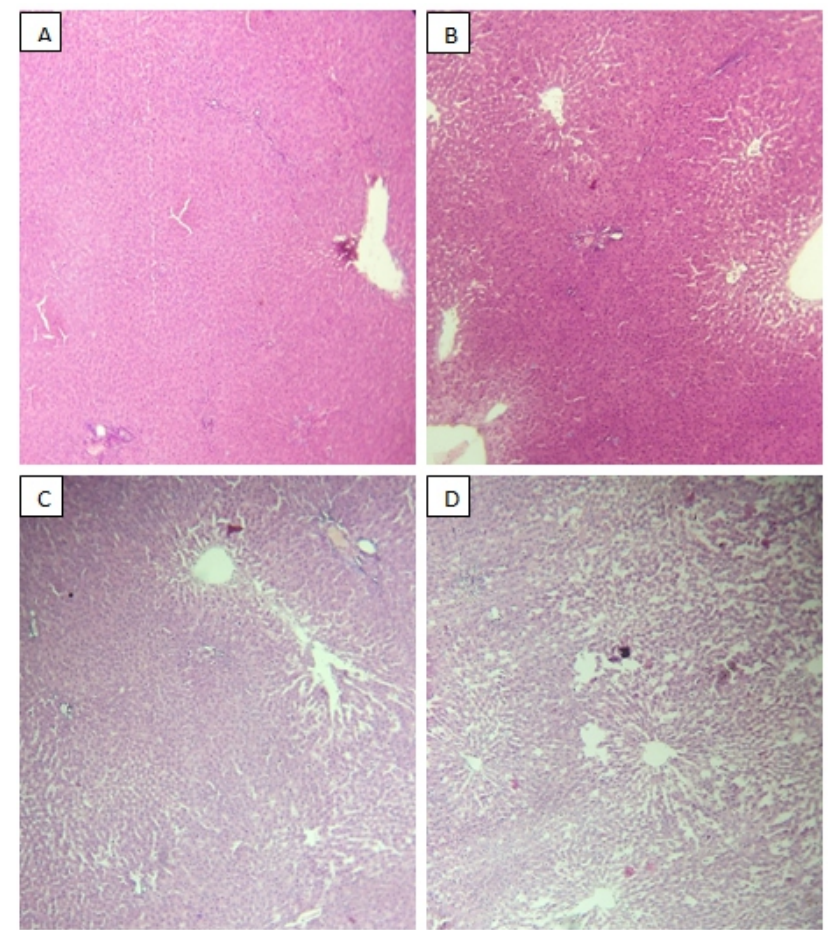

shown in figure 6. The sections show normal hepatic parenchyma, normal portal tract and vessels with no inflammatory cells seen in all the treated groups and the control animals.

Figure 6: Photomicrographs of Hepatic Tissue Showing the Morphology of Liver (hematoxylin and eosin stain with magnification of $\times 720$, and scale of $0.44 \mathrm{~mm})$

$\mathrm{A}=$ Control group, $\mathrm{B}=$ Dutasteride-Tamsulosin group, $\mathrm{C}=$ morin group and $\mathrm{D}=$ morin + Dutasteride/Tamsulosin group 
172 Olayinka \& Adewole: Morin Attenuates Dutasteride/Tamsulosin-Induced Hepatic Oxidative Stress in Rat

\section{DISCUSSION}

In this study, it was observed that DUT-TAM induced liver changes and altered the antioxidant status. However, co-treatment of DUT-TAM with morin offers protection against the observed hepatic damage. The significantly elevated plasma bilirubin level in the DUT-TAM treated animals suggests impairment in hepatic function. Morin administration with DUT-TAM was able to attenuate liver impairment occasioned by elevated plasma bilirubin level. Increased plasma bilirubin occurs when the liver cells are damaged, and there is obstruction of the intra and extra-cellular biliary tracts (Tredger and Sherwood, 1997; Renner, 2003).

Plasma aminotransferases (ALT and AST) are routinely used for assessing the integrity of the liver. The activities of these marker enzymes are usually raised above normal level when there is damage or necrosis to the hepatic cells (Zimmerman and Seeff, 1970). However, ALT is more specific for the liver tissue because the other enzymes and metabolites could be released as a result of damage to other organs. The elevated plasma ALT and AST by DUT-TAM is an indicator of hepatotoxicity. Co-treatment with morin plays highly significant protective role by attenuating the liver impairment brought about by the elevated plasma AST and ALT occasioned by DUT-TAM. Treatment with morin has been reported to prevent liver damage and to inhibit over-expression of radicals induced by various inflammatory stimuli (Milenkovic et al., 2012).

DUT-TAM treatment also led to a significant reduction in the activity of hepatic SOD and catalase. Morin was however able to ameliorate this decrease. The increase level of SOD activity after co-treatment with morin implies that morin is able to enhance the level of production of this antioxidant enzyme in the liver of rats. Catalase and SOD co-operate to prevent the deleterious effects of free radicals. Superoxide dismutase catalyzes the conversion of superoxide radical to hydrogen peroxide, while hydrogen peroxide is converted to innocuous oxygen and water. Accumulating hydrogen peroxide concentration inactivates SOD activity and this may leave the liver exposed to more hydrogen peroxide and hydroxyl-radical induced oxidative damage
(Adaramoye et al., 2005). Morin, a free radical scavenger, decreases the levels of oxidative stress markers (Milenkovic et al., 2012). Ascorbic acid is a known primary antioxidant (Frei, 1991), and this vitamin is thus an important systemic antioxidant which effectively mops up toxic free radicals in the body (Olayinka and Ore, 2014), but at the same time it is possibly very vulnerable to oxidation (Buettner and Moseley, 1993). From different studies, the systemic level of ascorbic acid has been shown to be a function of the systemic level of GSH (Stocker et al., 1986). DUT-TAM treatment significantly decreased the level of ascorbic acid, which in turn implies that an overwhelming effect of DUT-TAM-induced oxidative stress is expressed on systemic antioxidant indices. However, morin offers significant protection against the observed DUTTAM-induced hepatic oxidative stress.

DUT-TAM induced reduction in hepatic GST activity and GSH. Glutathione-S-transferase uses GSH in the metabolism and detoxification of various compounds, such as carcinogens and other xenobiotics, as well as various free radicals (Farombi et al., 2002). Glutathione conjugation is thus a protective mechanism by the body through which noxious radicals are scavenged as GSH conjugates. The reduced activity observed for GST is in tandem with hepatic GSH diminution; validating that DUT-TAM-induced toxicity is associated with systemic reduction of GSH (Aniya and Naito, 1993). Generally, GSH has been used as an important factor in assessing tissue susceptibility to oxidative onslaught, and the reduction in the level of GSH confirms the toxicity of chemicals (Adewole and Adebayo, 2017).

DUT-TAM induces significant increase in malondialdehyde (MDA) levels. Elevated hepatic MDA levels suggests an increased peroxidation of lipids (Olayinka et al., 2015). Generally, it has been shown that lipid peroxidation causes disruption of membrane structure, and thus, disruption of membrane fluidity and functions which may consequently lead to cell death (Devi et al., 2004). On treating with morin, the increase in the level of MDA was ameliorated. Thus, from investigations, morin has the capacity to inhibit oxidative stress 
caused by peroxidation of lipid by inhibiting the lipid peroxidation processes.

\section{CONCLUSION}

From this study, it may be suggested that dutasteride/tamsulosin impedes hepatic antioxidant system and causes degenerative changes. However, morin, a very potent antioxidant positively modulates the effect of the drug on the antioxidant status by ameliorating the oxidative damage and effectively protects against dutasteride/tamsulosin-induced hepatic oxidative stress, possibly as a result of its intrinsic antioxidant properties. The result obtained from this study serves as a basis for further studies to validate the protective effect of morin on DUTTAM-induced hepatic oxidative stress in other experimental models, especially in human subjects.

\section{REFERENCES}

Adaramoye, A., Nwaneri, V., Anyanwu, K., Farombi, E., Emerole, G., 2005. Possible anti-atherogenic effect of kolaviron (a Garcinia kola seed extract) in hypercholesterolaemic rats. Clinical and Experimental Pharmacology and Physiology, 32: 40-46.

Adewole, K.E., Adebayo, J.O., 2017. Antioxidant defense system induced by cysteinestabilized peptide fraction of aqueous extract of Morinda lucida leaf in selected tissues of Plasmodium berghei-infected mice. Journal of Integrative Medicine, 15: 388-397.

Ahmad, L., Mishra, A., Rahman, A., 2019. Protective role of hydroalcoholic extract of Cajanus cajan Linn leaves against memory impairment in sleep deprived experimental rats. Journal of Ayurveda and Integrative Medicine, e-pub ahead of print: 1-7.

Aniya, Y., Naito, A., 1993. Oxidative stressinduced activation of microsomal glutathione-S-transferase in isolated rat liver. Biochemical Pharmacology, 45: 3742.

Buettner, G., Moseley, P., 1993. EPR spin trapping of free radicals produced by bleomycin and ascorbate. Free Radical Research
Communication, 19: S89-S93

Chaudhary, S., Ganjoo, P., 2015. Nephroprotective activities of quercetin with potential relevance to oxidative stress induced by valproic acid. Protoplasma, 252: 209-217.

Devi, K.P., Sreepriya, M., Balakrishna, K., Devaki, T., 2004. Protective effect of Premna tomentosa (L. Verbenaceae) extract on membrane-bound phosphatases and inorganic cations transport in acetaminophen-induced hepatotoxicity rats. Journal of Ethnopharmacology, 93: 371-375.

Farombi, E., Adaramoye, A., Emerole, G., 2002. Influence of chloramphenicol on rat hepatic microsomal components and biomarkers of oxidative stress: protective role of antioxidants. Pharmacology $\varepsilon$ Toxicology, 91:129-134.

Frei, B., 1991. Ascorbic acid protects lipids in human plasma and low-density lipoprotein against oxidative damage. American Journal of Clinical Nutrition, 54:1113S-1118S.

Gornall, A.G., Bardawill, C.J., David, M.M., 1949. Determination of serum proteins by means of the biuret reaction. Journal of Biological Chemistry, 177: 751-766.

Habig, W.H., Pabst, M.J., Jakoby, W.B., 1974. Glutathione S transferases. The first enzymatic step in mercapturic acid formation. Journal of Biological Chemistry,. 249: 7130-7139.

Hamid, A.R., Umbas, R., Mochtar, C.A., 2011. Recent role of inflammation in prostate diseases: chemoprevention development opportunity. Acta Medicina Indonesia, 43: 59-65.

Jagota, S.., Dani, H.M., 1982. A new colorimetric technique for the estimation of vitamin $\mathrm{C}$ using Folin phenol reagent. Anals of Biochemistry, 127: 178-182.

Jollow, D.., Mitchell, J.., Zampaghone, N., Gillete, J.R., 1974. Bromobenzene induced liver necrosis, protective role of glutathione and evidence for 3,4-bromobenzene oxide as the hepatotoxic metabolite. Pharmacology, 11:151-169.

Joshi, G., Hardas, S., Sultana, R., St Clair, D., Vore, 
174 Olayinka \& Adewole: Morin Attenuates Dutasteride/Tamsulosin-Induced Hepatic Oxidative Stress in Rat

K., Butterfield, D., 2007. Glutathione elevation by $\mathrm{Y}$-glutamyl cysteine ethyl ester as a potential therapeutic strategy for preventing oxidative stress in brain mediated by in vivo administration of adriamycin: Implication for chemobrain. Neuroscience Research, 85: 497-503.

Kang, D.., Moon, M.., Sohn, E.., Lee, D.., Lee, H.., 2004. Effects of morin on blood pressure and metabolic changes in fructoseinduced hypertensive rats. Biological $\varepsilon$ Pharmaceutical Bulletin, 27, 1779-1783.

Krause, W.J., 2001. The art of examining and interpreting histologic preparations: A student handbook, 1 st edition. ed. CRC Press, Florida, USA.

Kurczewski, R., Bowen, C., Collins, D., Zhu, J., Serbest, G., Manyak, M., 2017. Bioequivalence studies of a reformulated Dutasteride and Tamsulosin Hydrochloride combination capsule and a commercially available formulation. Clinical Pharmacology and Drug Development, 6: 508-516

Kuzu, M., Yıldirım, S., Fatih Mehmet Kandemir, S.K., Çaglayan, C., Türk, E., Dörtbudak, M.B., 2019. Protective effect of morin on doxorubicin-induced hepatorenal toxicity in rats. Chemico Biological Interactions, 308: 89-100.

Middleton, E., Kandaswami, C., Theoharides, T., 2000. The effects of plant flavonoids on mammalian cells: implications for inflammation, heart disease, and cancer. Pharmacology Review, 52: 673-681.

Milenkovic, D., Đorovic, J., Dimitric, J.M., 2012. PM6 and DFT study of free radical scavenging activity of morin. Food Chemistry 134: 1754-1760.

Miller, J., Tarter, T., 2009. Combination therapy with dutasteride and tamsulosin for the treatment of symptomatic enlarged prostate. Clinical Intervention in Aging, 4:251-258.

Minciullo, P., Inferrera, A., Navarra, M., Calapai, G., Magno, C., Gangemi, S., 2015. Oxidative stress in benign prostatic hyperplasia: a systematic review. Urology International, 94: 249-254.

Misra, H.P., Fridovich, I., 1972. The role of superoxide anion in the autoxidation of epinephrine and a simple assay for superoxide dismutase. Journal of Biological Chemistry, 247: 3170-3175.

Mohamad, B.J., Obaid, H.H., Mohamad, D.I., Salim, M., 2017. Study the toxic effect of different doses of duprost in liver and blood of albino mice. Iraqi Journal of Science, 58: 1381-1392.

Olayinka, E.., Ore, A., 2014. Kolaviron and Lascorbic acid attenuate chlorambucilinduced testicular oxidative stress in rats. Journal of Toxicology, 2014:1-9

Olayinka, E., Ore, A., Adeyemo, O. A., Ola, O. S., 2019. The role of flavonoid antioxidant, morin in improving procarbazine-induced oxidative stress on testicular function in rat. Porto Biomedical Journal, 4: e28.

Olayinka, E. T., Ore, A., Adeyemo, O.A., 2015. Quercetin, a flavonoid antioxidant, ameliorated procarbazine-induced oxidative damage to murine tissues. Antioxidants, 4: 304-321.

Rattanachaikunsopon, P, Phumkhachorn, P., 2010. Contents and antibacterial activity of flavonoids extracted from leaves of Psidium guajava. Journal of Medicinal Plants Research, 4:393-396.

Reitman, S., Frankel, S., 1957. A colorimetric method for the determination of serum glutamic oxalacetic and glutamic pyruvic transaminases. American Journal of Clinical Pathology, 28: 56-63.

Renner, E.L., 2003. Liver function tests. Baillitre's Clinical Gastroenterology, 9: 661-676.

Ricardo, K., de Toledo, O. T., Nagem, T., Pinto, A., Oliveira, M., 2001. Effect of flavonoids morin; quercetin and nicotinic acid on lipid metabolism of rats experimentally fed with triton. Brazilian Archives of Biology and Technology, 44: 263-267.

Roehrborn, C., Boyle, P., JC, N., Hoefner, K., Andriole, G., 2002. Efficay and safety of dual inhibitor of 5-alpha-reductase types 1 and 2 (Dutasteride) in men with benign prostastic hyperplasia. Adult Urology, 60: 434-441.

Roehrborn, C. G., Perez, I. O., Roos, E. P. M., Calomfirescu, N., Brotherton, B., Wang, F., Palacios, J. M., Vasylyev, A., Manyak, M. 
J., 2015. Efficacy and safety of a fixeddose combination of dutasteride and tamsulosin treatment (Duodart ${ }^{\circledR}$ ) compared with watchful waiting with initiation of tamsulosin therapy if symptoms do not improve, both provided with lifestyle advice, in the management. BJU International, 116: 450-459.

Roehrborn, C.G., Siami, P., Barkin, J., Damião, R., Major-walker, K., Morrill, B., Montorsi, F., Study, C., 2008. The effects of dutasteride, tamsulosin and combination therapy on lower urinary tract symptoms in men with benign prostatic hyperplasia and prostatic enlargement: 2-year results from the combat study. Journal of Urology, 179: 616-621.

Sinha, A.K., 1972. Colorimetric assay of catalase. Anals of Biochemistry, 47:389-394.

Sreedharan, V., Venkatachalam KK, N.N., 2009. Effect of morin on tissue lipid peroxidation and antioxidant status in 1,2dimethylhydrazine induced experimental colon carcinogenesis. Investigational New Drugs, 27: 21-30.

Stocker, R., Weidemann, M.J., Hunt, N.H., 1986. Possible mechanisms responsible for the increased ascorbic acid content of Plasmodium vinckei-infected mouse erythrocytes. Biochemistry Biophysics Acta, 881:391-397.

Tietz, N.., Pruden, E.., Siggaard-Andersen, O., 1994. Liver function, in: Burtis, A..,
Ashwood, E.R. (Eds.), Tietz Textbook of Clinical Chemistry. Saunders, WB, London, UK, pp1354-1374.

Traish, A., Haider, K., Doros, G., Haider, A., 2017. Long-term dutasteride therapy in men with benign prostatic hyperplasia alters glucose and lipid profiles and increases severity of erectile dysfunction. Horm. Molecular Biology and Clinical Investigation, 30: 1-16.

Tredger, J.M., Sherwood, R.A., 1997. The liver: new functional, prognostic and diagnostic tests. Annals of Clinical Biochemistry, 34: 121-141.

Udensi, U.K., Tchounwou, P.B., 2016. Oxidative stress in prostate hyperplasia and carcinogenesis. Journal of Experimental and Clinical Cancer Research, 35:1-19.

Varshney, R., Kale, R.K., 1990. Effects of calmodulin antagonists on radiationinduced lipid peroxidation in microsomes. International Journal of Radiation Biology, 58: 733-743.

Zhang, R., Kang, K., Piao, M., Maeng, Y., Lee, K., Chang, W., You, H., Kim, J., Kang, S., Hyun, J., 2009. Cellular protection of morin against the oxidative stress induced by hydrogen peroxide. Chemico Biological Interaction, 177: 21-27.

Zimmerman, H.J., Seeff, L.B., 1970. Enzymes in Hepatic Disease, in: Coodley, E.L. (Ed.), Diagnostic Enzymology. Lea $\mathcal{E}$ Febiger, Philadelphia, pp1-38. 